\title{
Antimicrobial and antioxidant studies of novel mixed-metal complexes of benzoyl-aminoethanoic acid-nicotinamide: Microwave-assisted green synthesis, spectroscopic characterization and molecular modeling
}

\author{
Rayees Ahmad Shiekh*, Musa A Said", Maqsood Ahmad Malik², Athar Adil \\ Hashmi $^{2}$ \\ ${ }^{1}$ Department of Chemistry, Faculty of Science, Taibah University, PO Box 30002, Almadinah Almunawarrah, ${ }^{2}$ Chemistry \\ Department, Faculty of Science, King Abdulaziz University, PO Box 80203, Jeddah 21589, Saudi Arabia \\ ${ }^{*}$ For correspondence: Email: rayeeschem@gmail.com; Tel.: +966504439096
}

\begin{abstract}
Purpose: To enhance the antimicrobial and antioxidant activities of benzoylaminoethanoic acid (BAEA) and nicotinamide (NA).

Methods: Complexes of benzoylaminoethanoic acid (BAEA) and nicotinamide (NA) were prepared in a microwave oven. These metal complexes were evaluated by various techniques including $1 \mathrm{H}$ and $13 \mathrm{C}$ nuclear magnetic resonance spectrometry (NMR), infrared spectrometry (IR), ultraviolet-visible spectrometry (UV), mass spectrometry (MS), thermogravemetric analysis (TGA) and molar conductivity. The synthesized compounds were screened for both antibacterial and antifungal activities using disc diffusion technique. 1,1-Diphenyl-2-picrylhydrazyl (DPPH) radical scavenging method was used to assess the antioxidant activity of the complexes.

Results: Based on the results of spectroscopic techniques and physicochemical characterization, these complexes have been named [Cu(NA)2(BAEA)Cl2], [Co(NA)2(BAEA)Cl2], and [Ni(NA)2](BAEA)Cl2], respectively. A model structure with a distorted octahedron was proposed based on the outcome of the magnetic, analytical and spectral analyses. Synthesized metal complexes were more effective and efficient than nicotinamide and benzoylaminoethanoic acid.

Conclusion: Efficiently synthesized mixed metal complexes were prepared using a simple, eco-friendly rapid green chemistry methodology. The newly synthesized complexes have significant antimicrobial activities against the test bacterial and fungal strains.
\end{abstract}

Keywords: Antimicrobial agents, Antioxidant, Nicotinamide, Benzoylaminoethanoic acid, Mixed ligand complexes, Eco-friendly

This is an Open Access article that uses a funding model which does not charge readers or their institutions for access and distributed under the terms of the Creative Commons Attribution License (http://creativecommons.org/licenses/by/4.0) and the Budapest Open Access Initiative (http://www.budapestopenaccessinitiative.org/read), which permit unrestricted use, distribution, and reproduction in any medium, provided the original work is properly credited.

Tropical Journal of Pharmaceutical Research is indexed by Science Citation Index (SciSearch), Scopus, International Pharmaceutical Abstract, Chemical Abstracts, Embase, Index Copernicus, EBSCO, African Index Medicus, JournalSeek, Journal Citation Reports/Science Edition, Directory of Open Access Journals (DOAJ), African Journal Online, Bioline International, Open-J-Gate and Pharmacy Abstracts

\section{INTRODUCTION}

Medications with metals have shown success in therapeutic fields and are utilized as drug prescriptions against diabetes and tumors and for mitigating cardio-vascular illness [1]. Metal interactions involve a broad range of ligands and distinctive metal ions in various biological phenomena. These metal complexes have additionally been utilized as anti-bactericidal, 
anti-fungicidal, anti-tubercular and antiviral operators [2].

Nicotinamide is a colorless crystalline material with a unique smell and taste. Characteristic pyridine responses are observed for nicotinamide, and it can also a bond monodentate ligand through pyridine nitrogen [3]. In organic and biological frameworks, nicotinamide is involved in electron transport processes and is mixed with numerous enzymes to shape bi-co-enzymes [4]. It has developed flammable properties and further improves cell duplication in transplanted pancreatic islets [5]. The coordination of organically vital nicotinamide particles with transition metals is fundamental to understanding the impact of these metals in key organs. Accordingly, various nicotinamide compounds have been researched and explored both in terms of structure and spectroscopy [6]. Regardless of its microbial tendency, nicotinamide complexes are part of metalbiological structures, and are currently being researched for hydrogen storage applications.

Recently, coumarilate-nicotinamide complexes of $\mathrm{Co}$ (II) and $\mathrm{Zn}$ (II) and bis-nicotinamide dihalide(II) compounds were prepared and studied [7]. The synthesis of metal complexes has received attention due to their improved biological activities. The essential target of the present work is the synthesis, spectroscopic characterization, and biological evaluation of synthesized metal compounds.

\section{EXPERIMENTAL}

\section{Analytical measurements}

Metrix melting apparatus mechanical assembly evaluated the melting points of the synthetic compounds. An FT-IR Spectrometer (Bruker Tensor II) was utilized to collect the IR spectra of the incorporated metal complexes. Proton NMR $\left({ }^{1} \mathrm{H}\right.$ NMR) and Carbon-13 NMR $\left({ }^{13} \mathrm{C} \quad \mathrm{NMR}\right)$ integrated metal complexes were screened in $\mathrm{CDCl}_{3} / \mathrm{DMSO}-\mathrm{d}_{6}$ by utilizing tetramethylsilane (TMS) as an interior standard on a Bruker AVANCE DPX-600 spectrometer. A Bruker (esquire3000-00037) instrument was utilized to collect the mass spectra of complexes. TG/DTA (Thermal analysis) data was researched in a nitrogen environment utilizing a TG/DTA 6300 (SII Ex Star 6000) instrument. Estimations of the magnetic susceptibilities of powdered complexes were completed utilizing the Guoy's technique at normal room temperature. The reaction's progress and the purity of all metal complexes was observed by TLC utilizing silica gel $G$.

\section{Synthesis of mixed metal complexes}

Solutions of metal chloride (5 mM) [Cu(II) $1.23 \mathrm{~g}$, $\mathrm{Co}(\mathrm{II}) 1.19 \mathrm{~g}$, and $\mathrm{Ni}(\mathrm{II}) 1.19 \mathrm{~g}$ ] that were soluble in $25 \mathrm{~mL}$ of ethanol were mixed slowly in an ethanolic solution (25 $\mathrm{mL})$ of (BAEA) benzoylaminoethanoic acid (5 mM) and (NA) nicotinamide ligand (10 mM, $1.22 \mathrm{~g})$, with a molar ratio 1:1:2 (metal:BAEA:NA) with constant stirring. The final combination was reserved without interruption and irradiated at a constant standard power point $(600 \mathrm{~W})$ in microwave oven. The mixture was filtered and washed several times with $50 \%$ (v/v) water - ethanol to remove the non-reacted initial materials. The new complexes were greatly soluble in DMF/DMSO and faintly soluble in $\mathrm{CHCl}_{3}$. After evaporation, they were dehydrated over anhydrous $\mathrm{CaCl}_{2}$ in a desiccator.

\section{Molecular modeling studies}

The 3D atomic models of ligands $\left(L_{1}, L_{2}\right)$ and metal complexes were prepared in Ultra 14.1 Chem Bio 3D, a design program that allows the construction and geometry enhancement with the lowest energy and sub-atomic calculations. The correct stereochemistry was achieved by managing and modifying the molecular coordinates to acquire sensible, stumpy energy sub-atomic geometries. Numerous cycles of energy minimization must be prepared for every fragment to optimize statistical parameters approximating the bond lengths and bond edges in the ligands and metal complexes.

\section{Antimicrobial studies}

\section{Antibacterial screening}

Using the disk diffusion method, the synthesized complexes were checked using the $S$. pyogenes, E. coli, S. aureus, and $K$. pneumoniae bacterial strains. Ampicillin $(30 \mu \mathrm{g})$ was used as a positive control and a disc with DMSO as a negative control. Agar plates of Hinton-Muller containing samples at $25,50,75,100 \mu \mathrm{g} \mathrm{mL}^{-1}$ of prepared complexes were immunized with institutionalized inoculum for the tested strains of microorganisms (standard McFarland 0.5). The inoculum standard was absorbed onto the surface of the sterile agar plates. Discs measuring $10-\mathrm{mm}$ in breadth were prepared utilizing filter paper. The sterile plates already absorbed the known sample in the tested complexes set in medium agar nutrient and were stored at $5{ }^{\circ} \mathrm{C}$ for $1 \mathrm{~h}$ and then incubated at temperature $36{ }^{\circ} \mathrm{C}$ for $24 \mathrm{~h}$. A Muller- Hinton agar plate with no test compound was brooded with bacteria test strains and kept in the incubator. 


\section{Antifungal screening}

Antifungal activities were screened against the $C$. glabrata, C. albicans, C. krusei, C. tropicalis parasitic strains using the diffusion disk technique medium (potato dextrose agar) PDA. PDA plates containing test samples of $25,50,75$, $100, \mu \mathrm{g} \mathrm{mL}^{-1}$ of complexes were immunized with $100 \mu \mathrm{L}$ of a one-week-old spore suspension for every culture of fungi (108 spore/ mL). DMSO was absorbed by a filter paper disc of $10 \mathrm{~mm}$ and set aside for incubation at $32{ }^{\circ} \mathrm{C}$ for 48 hours. Then, the approximate inhibition zone diameter of every disc was calculated. A plate of PDA with untested compound was prepared for incubation using the strained test for fungi under similar conditions.

To understand the growth, $10^{6}$ cells/ mL (optical thickness A595 $=0.1$ ) of microbial cells were vaccinated and developed vigorously in YEPD broth for the control alongside various volumes of the test mixes in singular jars. Developments were calculated at $595 \mathrm{~nm}$ turbidometrically utilizing a spectrophotometer (USA, LaboMed Inc.) The development speed for a range of fungi in nonattendance with the addition of test mixes was determined for every fixation.

\section{Minimum inhibitory concentration (MIC)}

All investigated complexes were screened for the most minimal absorption of complexes without evident developmental parasites. The analysis was performed in triplicate, and averages were computed for antimicrobial action. The lowest absorption of every screened compound that had no obvious development of test fungi and microbes accounted for MIC in their accounted strains. It was also demonstrated that the DMSO in screened solutions had no influence on the test life forms. Outcomes were also determined for fluconazole/ampicillin for the fungal/bacterial strains as a positive control.

\section{Antioxidant activity}

2,2-Diphenyl-1-picrylhydrazyl (DPPH) [8] free species scavenging result assesses the antioxidant activity of synthesized compounds. DPPH is one of only a handful couple of stable and industrially accessible natural nitrogen singlets. DPPH radicals are measured to prescreen mixes that can scavenge activated oxygen varieties, as they are more stable and easier to use than oxygen free species. DPPH methods are the standard for determining antioxidant activity and offers a rapid technique for measuring the radical scavenging action of particular mixes or concentrates [9].
DPPH is a protected free species that can accept an electron or hydrogen radical and changes to a steady, diamagnetic chemical compound. DPPH has an odd electron and thus a solid assimilation band at $517 \mathrm{~nm}$. With successive dilutions, diverse content sample $(25,50$ and $75 \mu \mathrm{g})$ tests were established in DMSO. Three $\mathrm{mL}$ DPPH arrangements were included and stunned for approximately three $\mathrm{min}$ and stored in a dim space for thirty minutes at normal temperature (RT). Butylated hydroxy anisole (BHA) was utilized as a positive/reference control in various test tubes. A clear DPPH arrangement utilized pattern adjustment, since odd electrons in DPPH give solid absorption at $517 \mathrm{~nm}$ (using a Shimadzu UV-1601 spectrophotometer). Estimates of absorbance in each test tube were calculated at $517 \mathrm{~nm}$ after incubation, and modification (diminish) in the absorbance standards indicated the direct free species' searching action. Radical scavenging activity $(R)$ was computed as in Eq 1.

$R(\%)=\{(A c-A s) / A b) 100$

\section{Statistical analysis}

All the experiments were carried out in triplicate and the data presented as mean \pm standard deviation (SD). Statistical analysis was performed by SPSS version 22. Means for the test compound were compared with those of the reference compound by independent sample ttest at significance of $p>0.05$.

\section{RESULTS}

\section{$\mathrm{M}_{\text {comp1 }}\left[\mathrm{Co}(\mathrm{BAEA})(\mathrm{NA})_{2} \mathrm{Cl}_{2}\right.$ ]:}

The compound was recovered in the solid state. Purple, Yield $65 \%$, Mol. Wt. 540.06, m.p. > 300 ${ }^{0} \mathrm{C}$. UV-Vis (DMSO) $\mathrm{cm}^{-1}, 13,668$ - 13,923, $17,374-17,758,23,333-23,827, \mathrm{IR}\left(\mathrm{KBr}, \mathrm{cm}^{-1}\right)$ : $3476(\mathrm{NH}), 2987(\mathrm{CH}), 1725(\mathrm{CO}), 1396(\mathrm{CN})$, $1083\left(\mathrm{NH}_{2}\right), 851,728$; Far IR $\left(\mathrm{Csl}, \mathrm{cm}^{-1}\right) 448$ (CoO), 349 (CoCl). ${ }^{1} \mathrm{H}$ NMR, $300 \mathrm{MHz}$, (ppm $\delta$ TMS in $\left.\mathrm{CDCl}_{3}, 300 \mathrm{k}\right): \delta 9.97(1 \mathrm{H}$, br $\mathrm{N}-$ $\mathrm{H}, \mathrm{BAEA}$ ), $\delta 7.37-8.77$ ( $8 \mathrm{H}$, pyridine ring), $\delta$ $2.90\left(2 \mathrm{H}, \mathrm{HN}-\mathrm{CH}_{2}\right), \delta 7.30-7.90(4 \mathrm{H}$, pyridine ring $\left.\mathrm{O}=\mathrm{C}-\mathrm{NH}_{2}\right) \cdot{ }^{13} \mathrm{C} \mathrm{NMR}\left(\mathrm{CDCl}_{3}\right)(\delta, \mathrm{ppm})$ : 169-176 (4C = O (2 pyridine ring, 2 BAEA), 130 153 (pyridine ring 8C), $130-137$ (aromatic 5C), $42\left(\mathrm{CH}_{2}\right)$. ESI - MS (m/z) $540[\mathrm{M}]^{+}, 542[\mathrm{M}+1]^{+}$. Molar conductance, $\Lambda_{\mathrm{m}}\left(\Omega^{-1} \mathrm{~cm}^{-1} \mathrm{~mol}^{-1}, 10^{-3}\right.$ DMSO, r.t.): 16. $\mu$ eff (BM, r.t): 4.88. Elemt anals calcd $\mathrm{C}=46.70, \mathrm{H}=4.44, \mathrm{O}=11.85, \mathrm{~N}=12.96$ $\%$; found $\mathrm{C}=46.76, \mathrm{H}=4.49, \mathrm{O}=11.88, \mathrm{~N}=$ $12.99 \%$;

\section{$\mathrm{M}_{\text {comp2 }}\left[\mathrm{Ni}(\mathrm{BAEA})(\mathrm{NA})_{2} \mathrm{Cl}_{2}\right.$ ]:}

Trop J Pharm Res, May 2018; 17(5): 867 
Olive green, Yield 65 \%, Mol.Wt.539.82, m.p. > $300{ }^{0} \mathrm{C}$. UV-Vis (DMSO) $\mathrm{cm}^{-1}, 11,250$ - 11,631, 16,121 - 16,384, 27,353 - 27,997, IR, $\mathrm{KBr}, \mathrm{cm}^{-1}$ : $3465(\mathrm{NH}), 2957(\mathrm{CH}), 1730$ (CO), $1412(\mathrm{CN})$, $1075\left(\mathrm{NH}_{2}\right), 851,728$; Far IR $\left(\mathrm{Csl}, \mathrm{cm}^{-1}\right) 449$ (NiO), 339 (NiCl). ${ }^{1} \mathrm{H}$ NMR, $300 \mathrm{MHz}$, (ppm $\delta$ TMS, $\left.\mathrm{CDCl}_{3}, 300 \mathrm{k}\right): \delta 9.91(1 \mathrm{H}, \mathrm{br} \mathrm{NH}, \mathrm{BAEA}), \delta$ 7.33 - $8.67(8 \mathrm{H}$, pyridine ring), $\delta 2.70(2 \mathrm{H}, \mathrm{HN}$ $\left.\mathrm{CH}_{2}\right)$, $\delta 7.35$ - $7.95(4 \mathrm{H}$, pyridine ring $\mathrm{O}=\mathrm{C}$ $\left.\mathrm{NH}_{2}\right) \cdot{ }^{13} \mathrm{C}$ NMR $\left(\mathrm{CDCl}_{3}\right)(\delta, \mathrm{ppm}): 170-175(4 \mathrm{C}$ $=\mathrm{O}$ (2 pyridine ring, $2 \mathrm{BAEA}), 132$ - 155 (pyridine ring $8 \mathrm{C}$ ), 130 - 138 (aromatic $5 \mathrm{C}), 52\left(\mathrm{CH}_{2}\right)$. ESI - MS (m/z) $539[\mathrm{M}]^{+}, 540[\mathrm{M}+1]^{+}$. Molar conductance, $\Lambda_{\mathrm{m}}\left(\Omega^{-1} \mathrm{~cm}^{-1} \mathrm{~mol}^{-1}, 10^{-3} \mathrm{DMSO}\right.$, r.t.): 22. ueff (BM, r.t): 2.95. Elemt anals calcd $\mathrm{C}=$ 46.72, $\mathrm{H}=4.44, \mathrm{O}=11.85, \mathrm{~N}=12.85 \%$; found $\mathrm{C}=46.78, \mathrm{H}=4.46, \mathrm{O}=11.89, \mathrm{~N}=12.90 \%$;

\section{$\mathrm{M}_{\text {comp3 }}\left[\mathrm{Cu}(\mathrm{BAEA})(\mathrm{NA})_{2} \mathrm{Cl}_{2}\right]:$}

Pale blue. Yield $65 \%$, Mol. Wt. 544.67, m.p. > $300{ }^{\circ} \mathrm{C}$. UV-Vis (DMSO) $\mathrm{cm}^{-1}, 15,348$ - 54,723, 21,474 - 21,758, 22,957 - 23,527, IR ( $\left.\mathrm{KBr}, \mathrm{cm}^{-1}\right)$ : $3460(\mathrm{NH}), 2870(\mathrm{CH}), 1695(\mathrm{CO}), 1405(\mathrm{CN})$, $1103\left(\mathrm{NH}_{2}\right), 851,728$; Far IR $\left(\mathrm{Csl}, \mathrm{cm}^{-1}\right) 439$ (CuO), 345 (CuCl). ${ }^{1} \mathrm{H}$ NMR $300 \mathrm{MHz}$, (ppm $\delta$ TMS in $\left.\mathrm{CDCl}_{3}, 300 \mathrm{k}\right)$ : $\delta 9.92(1 \mathrm{H}$, br $\mathrm{N}$ $\mathrm{H}, \mathrm{BAEA}), \delta 7.32-7.97$ (8H, pyridine ring), $\delta$ 2.85(2H, $\left.\mathrm{HN}-\mathrm{CH}_{2}\right), \delta 7.28-7.88(4 \mathrm{H}$, pyridine ring $\left.\mathrm{O}=\mathrm{C}-\mathrm{NH}_{2}\right) .{ }^{13} \mathrm{C} \operatorname{NMR}\left(\mathrm{CDCl}_{3}\right)(\delta, \mathrm{ppm})$ : $172-178(4 \mathrm{C}=\mathrm{O}$ (2 pyridine ring, $2 \mathrm{BAEA}), 135$ - 163 (pyridine ring 8C), 128 - 135 (aromatic 5C), $56\left(\mathrm{CH}_{2}\right)$. ESI - MS (m/z) $545[\mathrm{M}]^{+}, 547[\mathrm{M}+1]^{+}$. Molar conductance, $\Lambda_{\mathrm{m}}\left(\Omega^{-1} \mathrm{~cm}^{-1} \mathrm{~mol}^{-1}, 10^{-3}\right.$ DMSO, r.t.): 25. $\mu$ eff (BM, r.t): 1.92. Elemt anals calcd $\mathrm{C}=46.30, \mathrm{H}=4.40, \mathrm{O}=11.75, \mathrm{~N}=12.85$ $\%$; found $\mathrm{C}=46.36, \mathrm{H}=4.42, \mathrm{O}=11.79, \mathrm{~N}=$ $12.92 \%$, data shown in Table 1.

\section{Infrared spectra}

Nicotinamide (NA) generally bonds its nitrogen to metal ions at the pyridine ring or oxygen/nitrogen in the amide group. Peaks for $\mathrm{v}(\mathrm{NH})$ amide type $3374 \mathrm{~cm}^{-1}$ and (amide I) v(CO)frequency at 1668 $\mathrm{cm}^{-1}$ were increased to higher frequencies, at 3380 - $3430 \mathrm{~cm}^{-1}$ and $1671-1750 \mathrm{~cm}^{-1}$, respectively, in the complexes representing non- intervention of the nitrogen/oxygen of the amide group [9]. Peaks at approximately 1573 - 1520 $\mathrm{cm}^{-1}$ and 1066 - $1030 \mathrm{~cm}^{-1}$ in complexes respectively signified asymmetric and symmetric stretching of the $[\mathrm{v}(\mathrm{C}=\mathrm{N})+\mathrm{v}(\mathrm{C}=\mathrm{C})]$ ring bearing pyridine, at lesser frequencies than to nicotinamide ligand. Therefore, the $\mathrm{C}=\mathrm{O}$ bond is reduced and the $\mathrm{C}=\mathrm{N}$ bond is stretched to their respective frequencies during complexation. Amide II (1412 $\left.\mathrm{cm}^{-1}\right)$ and amide III $\left(1240 \mathrm{~cm}^{-1}\right)$ correspond to $v(C-N)$ and $v(N-H)$ modes (attached together) in the nicotinamide during complexation and shifted to higher frequencies at 1435 - 1510 and at 1298 - $1320 \mathrm{~cm}^{-1}$ respectively, clarifying the non-involvement of the amide group [10].

\section{IR bands due to anions}

In the spectra of the complexes, new bands were seen in the ranges $540-530 \mathrm{~cm}^{-1}$ to $492-470$ $\mathrm{cm}^{-1}$ that were not present in the spectrum of the ligand for v(Metal - Nitrogen), v(Metal - Oxygen) vibrations, respectively. Complexation showed that carbonyl species nearer to the metal ion center had less M - L bond space. Another average-strength band was seen at $337-368$ $\mathrm{cm}^{-1}$ and corresponded to the $\mathrm{v}$ (Metal - Chlorine) of complexes $\mathrm{LM}_{1}, \mathrm{LM}_{2}$ and $\mathrm{LM}_{3}$.

\section{${ }^{1}$ H NMR spectra}

In the pure un-reacted NA ligand peak positions corresponded to $9.09(1 \mathrm{H}(1)$, pyridine ring $\mathrm{PR})$, $8.76(1 \mathrm{H}(2), \mathrm{PR}), 8.29(1 \mathrm{H}(3), \mathrm{PR}), 7.59(1 \mathrm{H}(6)$, pyridine ring), 8.30 and $7.67\left(2 \mathrm{H}, \mathrm{NH}_{2}\right.$ of amide group) $\delta(p p m)$ [11]. Similarly, uncoordinated pure benzoyl-aminoethanoic acid had peaks corresponding to $\delta(\mathrm{ppm}) 7.52-7.55(\mathrm{~m}, 2 \mathrm{H}$, phenyl ring), 7.81 - $7.83(\mathrm{~m}, 2 \mathrm{H}$, phenyl ring), 7.61 - $7.64\left(\mathrm{~m}, 1 \mathrm{H}\right.$, benzene ring), $3.96\left(2 \mathrm{H}, \mathrm{CH}_{2}\right)$, and $8.30(1 \mathrm{H}, \mathrm{NH}$ of amide group).

All proton signals underwent down-field shifting due to the paramagnetic behavior in metal complexes, and as a result the coordination of the ligand with metal ions was maintained [12].

Table 1: Analytical data and physical properties of the complexes

\begin{tabular}{llllcccccc}
\hline Compound & Color & $\mathbf{M C}$ & $\begin{array}{c}\text { MP } \\
\left.{ }^{0} \mathbf{C}\right)\end{array}$ & $\begin{array}{c}\text { Mol. wt } \\
\text { found } \\
\text { (calculated) }\end{array}$ & $\mathbf{M}$ & $\mathbf{C}$ & $\mathbf{H}$ & $\mathbf{N}$ & $\mathbf{O}$ \\
\hline $\mathrm{M}_{\text {comp1 }}$ & Purple & 18 & $>300$ & $540.06(541.25)$ & 10.91 & 46.70 & 4.44 & 12.96 & 11.85 \\
& & & & & $(10.95)$ & $(46.76)$ & $(4.49)$ & $(12.99)$ & $(11.88)$ \\
$M_{\text {comp2 }}$ & Olive & 23 & $>300$ & $539.82(540.92)$ & 10.87 & 46.72 & 4.44 & 12.85 & 11.85 \\
& green & & & & $(10.90)$ & $(46.78)$ & $(4.46)$ & $(12.90)$ & $(11.89)$ \\
$M_{\text {comp3 }}$ & Pale & 26 & $>300$ & $544.67(545.85)$ & 11.66 & 46.30 & 4.40 & 12.85 & 11.75 \\
& blue & & & & $(11.70)$ & $(46.36)$ & $(4.42)$ & $(12.92)$ & $(11.79)$ \\
\hline
\end{tabular}

$\mathrm{MC}=$ molar conductance 
Upon screening peaks of ligand, complexes, experimental observations showed protons of pyridine rings reveal a lower shift and that of protons of amide exhibit a higher shift, which showed that NA-metal coordination through $\mathrm{N}$ (nitrogen)in pyridine ring.

\section{${ }^{13} \mathrm{C}$ NMR spectra}

The ${ }^{13} \mathrm{C}$ NMR spectra of the $\left(\mathrm{L}_{1}, \mathrm{~L}_{2}\right)$ ligands and complexes was screened and characterized. Uncoordinated pure Ligand $\left(\mathrm{L}_{1}\right)$ showed a pointed signal at $180 \mathrm{ppm}$ that corresponds to two $\mathrm{C}=\mathrm{O}$ carbons. Two signals appear at 126 and $138 \mathrm{ppm}$, corresponding to the aromatic carbons of the benzene ring. Similarly, uncoordinated pure ligand $\left(L_{2}\right)$ shows a spiky signal at $166 \mathrm{ppm}$ that matches the $\mathrm{C}=\mathrm{O}$ carbons of the nicotinamide ring. Two signals appeared at 123 and $151 \mathrm{ppm}$ and have been ascribed to the aromatic carbons of the nicotinamide rings. All carbon peaks experienced a downward shift in the metals during complexation, which was responsible for the paramagnetic results for the metal (II) ions.

\section{Mass spectra}

The negative ion mass peaks at $\mathrm{m} / \mathrm{z} 541,542$, and 545 , respectively, reliably correspond to the cobalt(II), nickel(II), copper(II) chloride complexes among the molecular ion fragments. The $[\mathrm{M}+2]^{+}$peaks are seen in complexation, possibly due to their occurrence in chlorine isotopes at a lower concentration [13] Figure 1. Sometimes, the molecular ion signal included solvent water molecules as an adduct [14].

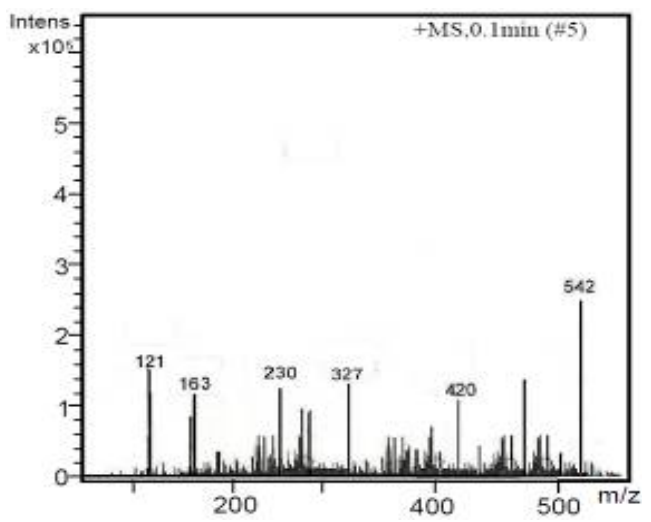

Figure 1: Electrospray ionization mass spectra (ESI$\mathrm{MS}$ ) of the $\mathrm{M}_{\text {comp2 }}(\mathrm{Ni}(\mathrm{II})$ complex)

\section{Electronic spectra and magnetic data}

\section{Cobalt (II) complex ( $\left.M_{\text {comp1 }}\right)$}

A DMSO solution was used to calculate the electronic spectra of the metal complexes. The
Co(II) complex displays a range of absorption in the ranges $12,568-12,852,15,554-15,885$, $22,543-22,927$ and $31,520-32,335$. These bands correspond to ${ }^{4} \mathrm{~T}_{1 \mathrm{~g}}(\mathrm{~F}) \rightarrow{ }^{4} \mathrm{~T}_{2 \mathrm{~g}}(\mathrm{~F})\left(\mathrm{V}_{1}\right),{ }^{4} \mathrm{~T}_{1 \mathrm{~g}}$ $\rightarrow{ }^{4} \mathrm{~A}_{2 g}\left(\mathrm{~V}_{2}\right)$ and ${ }^{4} \mathrm{~T}_{1 \mathrm{~g}}(\mathrm{~F}) \rightarrow{ }^{4} \mathrm{~T}_{2 \mathrm{~g}}(\mathrm{P})\left(\mathrm{V}_{3}\right)$, respectively signifying an octahedral geometry around the Cobalt(II) ion [15]. The magnetic moments of $M_{\text {comp1 } 1}$ were found at 4.88B.M, analogous to the 3 unpaired electrons at room temperature [16].

\section{Nickel (II) complex ( $M_{\text {comp2 }}$ )}

The Nickel(II) complex displayed 3 absorption peaks in the ranges $11,230-11,15,890$ 16,354 and $25,535-26,987$, corresponding to ${ }^{3} \mathrm{~A}_{2 g}(\mathrm{~F}) \rightarrow{ }^{3} \mathrm{~T}_{2 g}(\mathrm{~F})\left(\mathrm{U}_{1}\right),{ }^{3} \mathrm{~A}_{2 g}(\mathrm{~F}) \rightarrow{ }^{3} \mathrm{~T}_{1 \mathrm{~g}}(\mathrm{~F})(\mathrm{U} 2)$, and ${ }^{3} \mathrm{~A}_{2 g}(\mathrm{~F}) \rightarrow{ }^{3} \mathrm{~T}_{1 g}(\mathrm{P})(\mathrm{U} 3)$, respectively [17]. The magnetic moment of $M_{\text {comp2 }}$ was found at 2.95 B.M, corresponding to 2 unpaired electrons at room temperature. Therefore, the spectral activities of the complexes exhibited an octahedral 6-coordinated geometry (Scheme 1).

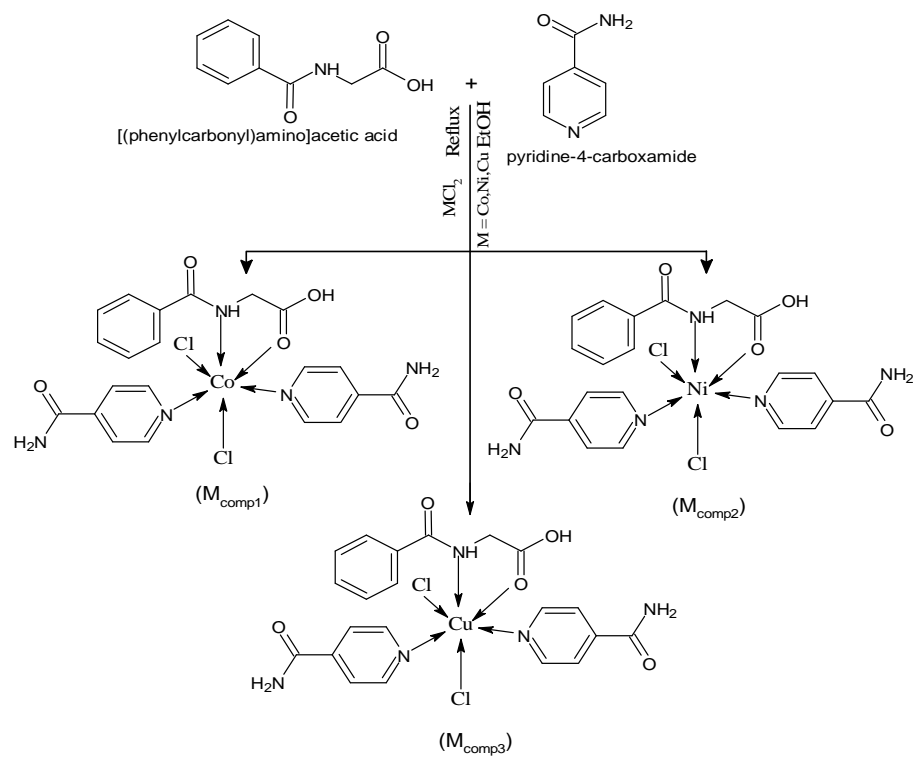

Scheme 1: Mixed benzoyl-aminoethanoic acidnicotinamide metal complexes

\section{Copper (II) complex ( $M_{\text {comp3 }}$ )}

The Ni(II) complex demonstrated 3 absorption peaks in the ranges $13,634-14,122,18,920-$ 20,568 and 22,127 - 22,655, corresponding to ${ }^{3} \mathrm{~A}_{2 g}(\mathrm{~F}) \rightarrow{ }^{3} \mathrm{~T}_{2 g}(\mathrm{~F})\left(\mathrm{U}_{1}\right),{ }^{3} \mathrm{~A}_{2 g}(\mathrm{~F}) \rightarrow{ }^{3} \mathrm{~T}_{1 \mathrm{~g}}(\mathrm{~F})(\mathrm{U} 2)$, and ${ }^{3} \mathrm{~A}_{2 g}(\mathrm{~F}) \rightarrow{ }^{3} \mathrm{~T}_{1 \mathrm{~g}}(\mathrm{P})(\mathrm{U} 3)$, respectively [18]. The magnetic moment in $\mathrm{M}_{\text {comp3 }}$ was found at 1.92 B.M, analogous to 2 unpaired electrons.

\section{Thermogravimetric data}

\section{Metal complexes}

The TGA technique finds the coupled solvent/ 
water moieties in a crystalline form or coordination form [19].

The thermogram of the metal complexes does not display any bands below $150{ }^{\circ} \mathrm{C}$, signifying the absence of a water moiety. The thermogram of $\mathrm{Co}(\mathrm{II}), \mathrm{Ni}(\mathrm{II})$ and $\mathrm{Cu}(\mathrm{II})$ compounds was constant and showed resistance up to 210, 206 and $15{ }^{0} \mathrm{C}$ respectively. In nickel complex, (Figure 2) shows two endothermic peaks one a major step of decomposition from $160-340{ }^{\circ} \mathrm{C}$ which is calculated by DTA at $206{ }^{\circ} \mathrm{C}$, this confirms loss of two nicotinamide moieties and one benzoylaminoethanoic acid moiety (observed weight $75.66 \%$, theoretical weight $78.5 \%$ ) and next endothermic peak at $540{ }^{\circ} \mathrm{C}$ confirms the melting, the first and second band on the DTA curve which is detected at $630^{\circ} \mathrm{C}$.

\section{Antimicrobial activity}

Antibacterial and antifungal studies have been used to check the microbial activity of tested compounds against different bacterial and fungal species. Table 2 and Table 3 show the bacterial and fungal growth inhibition in millimeters against different bacterial and fungal species at 100 $\mu \mathrm{g} / \mathrm{mL}$ concentration respectively. Data given in table 2 shows that metal compounds has higher activity than the ligand $L_{1}$ and $L_{2}$ against both bacterial and fungal species with respect to reference drug ampicillin and fluconazole, respectively.

\section{Minimum inhibitory concentration}

Minimum inhibitory concentration is the smallest concentration of test compounds used to check the activity against different bacterial/fungal species. Data given in Table 4 and Table 5 show the concentration in minimum values of tested compounds used against bacterial/fungal species with respect to standard drug ampicillin/fluconazole, respectively.

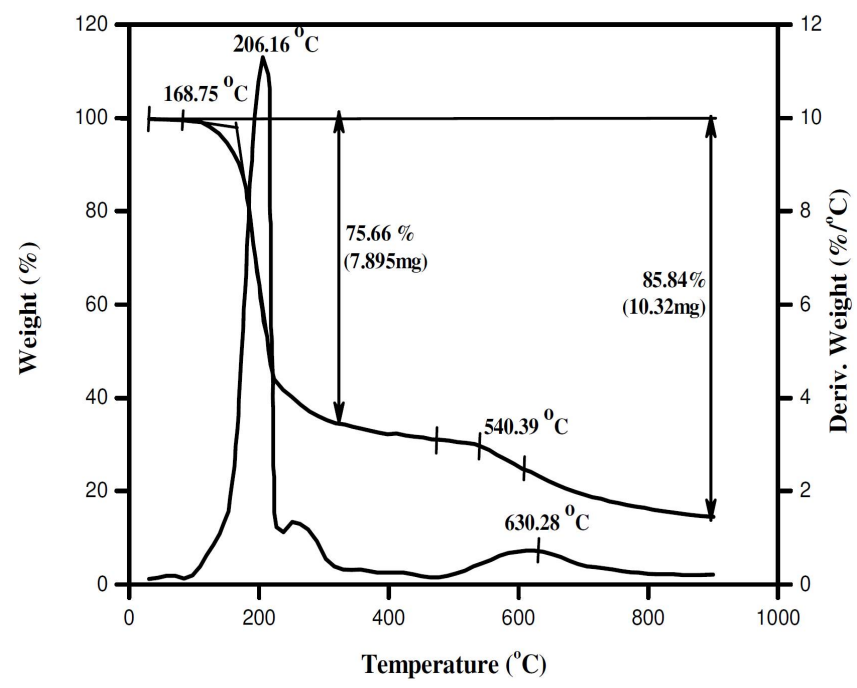

Figure 2: Thermograms (TGA/DTA) of $\mathrm{M}_{\mathrm{comp} 2} \mathrm{Ni}(\mathrm{II})$ complex

Table 2: Bacterial growth inhibition in millimetres $(\mathrm{mm})$ for different compounds at $100 \mu \mathrm{g} / \mathrm{mL}$ concentration; ampicillin (AMP) used as reference compound

\begin{tabular}{lcccc}
\hline Variable & \multicolumn{4}{c}{ Bacterial species } \\
\cline { 2 - 5 } & S. aureus & S. pyrogenes & E. coli & K. pneumoniae \\
\hline $\mathrm{L}_{1}$ & $5.00 \pm 0.25$ & $4.00 \pm 0.20$ & $7.00 \pm 0.35$ & $5.00 \pm 0.25$ \\
$\mathrm{~L}_{2}$ & $4.00 \pm 0.20$ & $5.00 \pm 0.25$ & $9.00 \pm 0.45$ & $10.00 \pm 0.50$ \\
Mcomp $_{1}$ & $17.00 \pm 0.85$ & $14.00 \pm 0.72$ & $13.00 \pm 0.65$ & $16.00 \pm 0.80$ \\
Mcomp $_{2}$ & $19.00 \pm 0.95$ & $17.00 \pm 0.68^{*}$ & $17.00 \pm 0.85$ & $15.00 \pm 0.75$ \\
Mcomp & $16.00 \pm 0.80$ & $12.00 \pm 0.65$ & $14.00 \pm 0.70$ & $15.00 \pm 0.75$ \\
AMP & $23.00 \pm 1.15$ & $19.00 \pm 0.95$ & $21.00 \pm 1.05$ & $22.00 \pm 1.10$ \\
\hline
\end{tabular}

Values are mean \pm SD of three separate experiments; ${ }^{*}$ mean comparable with AMP

Table 3: Fungal growth inhibition in millimeteres $(\mathrm{mm})$ for different compounds at $100 \mu \mathrm{lg} / \mathrm{mL}$ concentration; Fluconazole (FLU) used as reference compound

\begin{tabular}{lcccc}
\hline Variable & \multicolumn{3}{c}{ Fungal species } \\
\cline { 2 - 5 } & C. albicans & C. glabrata & C. tropicalis & C. krusei \\
\hline $\mathrm{L}_{1}$ & $6.00 \pm 0.30$ & $5.00 \pm 0.25$ & $6.00 \pm 0.30$ & $5.00 \pm 0.25$ \\
$\mathrm{~L}_{2}$ & $7.00 \pm 0.35$ & $8.00 \pm 0.40$ & $9.00 \pm 0.45$ & $11.00 \pm 0.55$ \\
Mcomp $_{1}$ & $12.00 \pm 0.60$ & $13.00 \pm 0.65$ & $14.00 \pm 0.70$ & $12.00 \pm 0.60$ \\
Mcomp $_{2}$ & $18.00 \pm 0.90$ & $17.00 \pm 0.85$ & $17.00 \pm 0.85$ & $16.00 \pm 0.80$ \\
Mcomp & $17.00 \pm 0.85$ & $15.00 \pm 0.75$ & $15.00 \pm 0.75$ & $12.00 \pm 0.60$ \\
FLU & $22.00 \pm 1.10$ & $21.00 \pm 1.05$ & $20.00 \pm 10$ & $21.00 \pm 1.05$ \\
\hline
\end{tabular}

Values are mean \pm SD of three separate experiments 
Table 4: Minimum inhibitory concentrations (MIC) of ligands and its metal complexes against different bacterial species

\begin{tabular}{lcccc}
\hline & \multicolumn{3}{c}{ Bacterial species } \\
\cline { 2 - 5 } & S.aureus & S.Pyrogenes & E.coli & K.pneumoniae \\
\hline $\mathrm{L}_{1}$ & $310 \pm 12.5$ & $320 \pm 11.90$ & $425 \pm 16.25$ & $430 \pm 16.35$ \\
$\mathrm{~L}_{2}$ & $290 \pm 10.5$ & $310 \pm 11.50$ & $390 \pm 14.50$ & $400 \pm 15.15$ \\
Mcomp $_{1}$ & $82 \pm 4.10$ & $79 \pm 3.95$ & $90 \pm 3.90$ & $88 \pm 4.40$ \\
Mcomp $_{2}$ & $78 \pm 3.90$ & $75 \pm 3.75$ & $70 \pm 3.50$ & $80 \pm 4.21$ \\
Mcomp $_{3}$ & $89 \pm 4.45$ & $85 \pm 4.25$ & $77 \pm 3.85$ & $83 \pm 4.15$ \\
AMP & $53 \pm 2.65$ & $52 \pm 2.60$ & $51 \pm 2.55$ & $53 \pm 2.65$ \\
\hline
\end{tabular}

Values are mean \pm SD of three separate experiments

Table 5: Minimum inhibitory concentrations (MIC) of ligands and its metal complexes against different fungal species

\begin{tabular}{lcccc}
\hline Variable & \multicolumn{4}{c}{ Fungal species } \\
\cline { 2 - 5 } & C. albicans & C. glabrata & C. tropicalis & C. krusei \\
\hline $\mathrm{L}_{1}$ & $180 \pm 7.21$ & $330 \pm 10.50$ & $350 \pm 14.5$ & $270 \pm 13.50$ \\
$\mathrm{~L}_{2}$ & $170 \pm 6.50$ & $315 \pm 9.75$ & $330 \pm 12.5$ & $260 \pm 13.14$ \\
Mcomp $_{1}$ & $75 \pm 3.75$ & $85 \pm 4.25$ & $84 \pm 4.20$ & $85 \pm 4.25$ \\
Mcomp $_{2}$ & $65^{\star} \pm 3.25$ & $70 \pm 3.50$ & $80 \pm 4.05$ & $78 \pm 3.91$ \\
Mcomp $_{3}$ & $78 \pm 3.90$ & $95 \pm 4.75$ & $95 \pm 4.75$ & $100 \pm 4.09$ \\
FLU & $62 \pm 3.10$ & $60 \pm 3.12$ & $53 \pm 2.65$ & $52 \pm 2.60$ \\
\hline Values are mean \pm SD of three separate experiments; ${ }^{*}$ mean comparable with FLU
\end{tabular}

\section{Antioxidant activity}

2,2-Diphenyl-1-picrylhydrazyl (DPPH) free species scavenging result assesses antioxidant activity of synthesized compounds. DPPH is used to check antioxidant activity and offers a rapid technique for viewing the radical scavenging action of particular mixes or concentrates. Data given in Table 6 show the antioxidant activity values of ligands and its metal compounds at different concentrations against the reference drug butylated hydroxy anisole (BHA). This experiment is totally based on free radical absorption pattern. All free radical scavenging results were computed with equation 1 as given in experimental part.

Table 6: Antioxidant activity of ligands $\left(\mathrm{L}_{1}\right.$ and $\left.\mathrm{L}_{2}\right)$ and their metal complexes

\begin{tabular}{lcccc}
\hline Variable & \multicolumn{4}{c}{ Concentration } \\
\cline { 2 - 5 } & $\mathbf{2 5} \boldsymbol{\mu g}$ & $\mathbf{5 0} \boldsymbol{\mu g}$ & $\mathbf{7 5} \boldsymbol{\mu g}$ & $\mathbf{1 0 0} \boldsymbol{\mu g}$ \\
\hline $\mathrm{L}_{1}$ & $5 \pm 0.25$ & $7 \pm 0.35$ & $9 \pm 0.45$ & $10 \pm 0.50$ \\
$\mathrm{~L}_{2}$ & $7 \pm 0.35$ & $9 \pm 0.45$ & $10 \pm 0.50$ & $13 \pm 0.65$ \\
Mcomp $_{1}$ & $25 \pm 1.25$ & $37^{\star} \pm 1.85$ & $52^{*} \pm 2.60$ & $59^{\star} \pm 2.95$ \\
Mcomp $_{2}$ & $43^{\star} \pm 2.15$ & $58^{\star} \pm 2.90$ & $64^{\star} \pm 3.20$ & $73^{\star} \pm 3.65$ \\
MComp $_{3}$ & $35 \pm 1.75$ & $40 \pm 2.08$ & $55^{\star} \pm 2.75$ & $64^{\star} \pm 3.20$ \\
$\mathrm{BHA}$ & $49 \pm 2.45$ & $53 \pm 2.65$ & $61 \pm 3.05$ & $79 \pm 3.95$ \\
\hline
\end{tabular}

Values are mean \pm SD of three separate experiments; *Mean comparable with BHA

\section{Molecular models}

Geometry optimization was achieved using CHEM 3D Ultra software for ligands $\left(L_{1}, L_{2}\right)$ and metal complexes (Figure 3 and Figure 4. Many cycles of energy minimization were performed for each molecule. Some parameters, including bond lengths/angles, were constrained. The definite bond lengths/angles in (Supplementary file, Tables 1-10) were designed with values resulting from energy optimization in CHEM 3D Ultra; the best possible bond length/optimal bond angle data were primarily pleasing/constructive (standard) bond lengths/angles that were recognized in CHEM 3D. The absence of several standard bond lengths/angles correspond to software restrictions, as previously mentioned in modeling studies [20]. In the majority of experiments, actual bond lengths/angles were matched to optimal values, and hence the projected structures of tested complexes are acceptable [20].

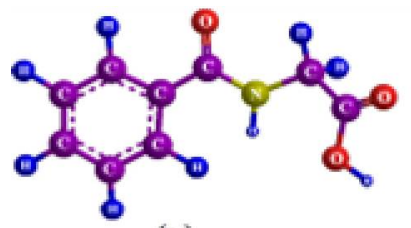

(a)

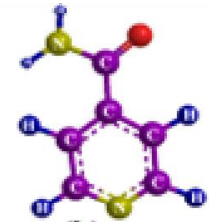

(b)

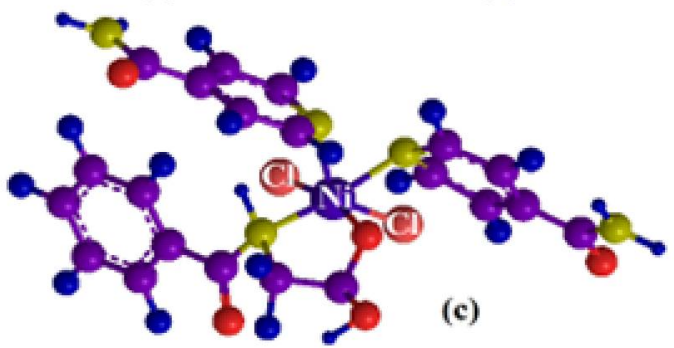

Figure 3: Geometry-optimized structure of (a) $L_{1}$ (b) $L_{2}$ and (c) $\mathrm{Ni}(\mathrm{II})$ metal complexes 


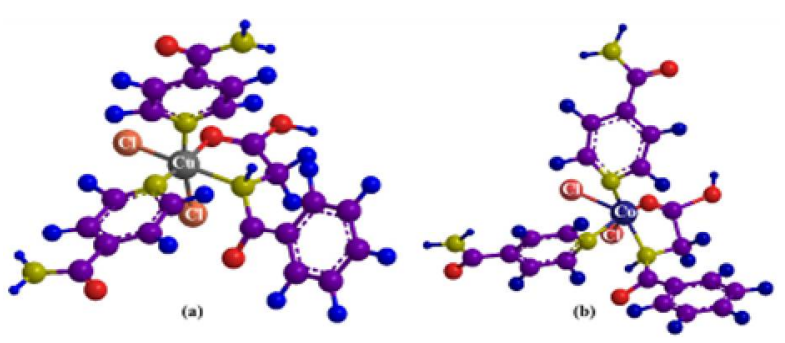

Figure 4: Geometry-optimized structure of (a) $\mathrm{Cu}$ (b) Co-metal complex

\section{Growth curve activity (GCA)}

Increasing concentrations of ligand and mixed metal complexes were studied with the growth of various fungal/bacterial species. A typical guide for growth was observed in control cells with a lag phase of $4 \mathrm{~h}$ and an energetic exponential stage of $8-10 \mathrm{~h}$ before reaching a constant phase. As we increase the concentration of the tested compounds growth will decrease, as seen in C. albicans at a concentration of $50 \mu \mathrm{g} / \mathrm{mL}$ against the $\mathrm{Ni}$ (II) metal complex, the lag phase increases by $2 \mathrm{~h}$, as the immobile (stationary) phase does not reach similar increases in cell growth as the that in control; the $100 \mu \mathrm{g} / \mathrm{ml} \mathrm{lag}$ phase becomes more extensive over the 2-hour period. At the $125 \mu \mathrm{g} / \mathrm{ml} \quad\left(\mathrm{MIC}_{80}\right.$ level) concentration, a complete inhibition in growth was shown by a horizontal line (Figure 5). Fluconazole at $20 \mu \mathrm{g} / \mathrm{mL}$ shows additional extension by $6 \mathrm{~h}$ in the lag phase compared to the control. Noteworthy and prominent results were observed in all synthesized complexes. Various concentrations of metal complexes suppressed growth and deferred the exponential phases. A complete inhibition in growth was observed at the $\mathrm{MIC}_{80}$.

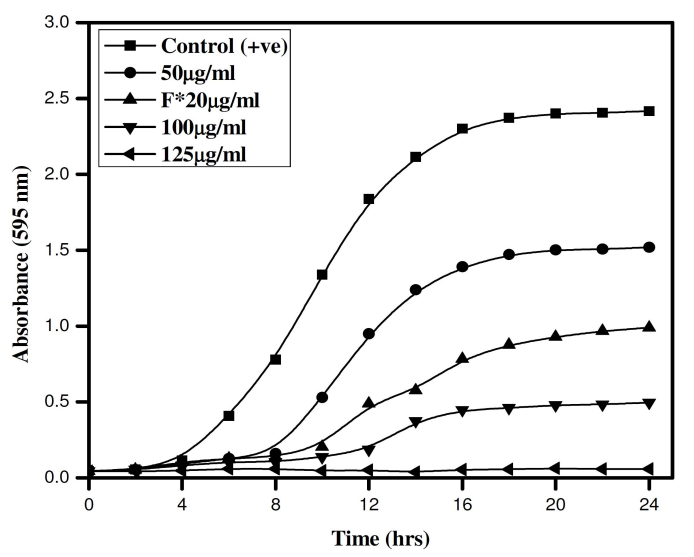

Figure 5: Effect of $\mathrm{Ni}(\mathrm{II})\left(\mathrm{M}_{\mathrm{comp}}\right)$ complex over concentration range of $50-125 \mu \mathrm{g} / \mathrm{ml}$ studied in $C$. albicans ATCC10261. Growth curve plotted against absorbance at $595 \mathrm{~nm}$ with time (hrs) shows complete inhibition of growth at $125 \mu \mathrm{g} / \mathrm{ml}$

\section{DISCUSSION}

The synthesis of the mixed complexes was achieved according to the procedure shown in (Schemes 1). Benzoylaminoethanoic acid (BAEA) and nicotinamide (NA) were cyclized with metal chloride salts in the molar ratio 1:1:2 (metal: BAEA: NA). The analytical figures of metal complexes corresponded to the general formula $\left[\mathrm{ML}_{1} \mathrm{~L}_{2} \mathrm{X}_{2}\right]$, where $(\mathrm{M}=\mathrm{Ni}(\mathrm{II}), \mathrm{Co}(\mathrm{II})$, $\mathrm{Cu}(\mathrm{II})) \mathrm{L}_{1}=$ benzoylaminoethanoic acid; $\mathrm{L}_{2}=$ nicotinamide, and $\mathrm{X}=\mathrm{Cl}^{-}$. Molar conductance values showed a non-electrolytic complex in DMSO $\left(10^{-3} \mathrm{M}\right)$ near the ground, to check for dissociation (Table 1).

Results from IR and NMR spectroscopy confirms that the $\mathrm{C}=\mathrm{O}$ bond is reduced and the $\mathrm{C}=\mathrm{N}$ bond is stretched to their respective frequencies during complexation. IR results also shows (Metal - Nitrogen), (Metal - Oxygen) vibrations, which confirm that the complexation takes place through nitrogen and oxygen of the parent ligand. Mass spectroscopy of metal complexes shows a mass ion peak that corresponds to the concerned metal ion moieties.

Antimicrobial studies of the synthesized complexes on selected Gram-positive bacteria (S. aureus, S. pyogenes), Gram-negative bacteria ( $E$. coli, K. pneumoniae) and the fungi $C$. albicans, C. glabrata, C. tropicalis and C. krusei were determined in vitro. The synthesized compounds showed high-quality biological activity against all tested microorganisms. Interestingly, the synthesized compounds exhibited higher antimicrobial study than the ligands $\left(L_{1}, L_{2}\right)$. Coordination enhanced the activity of the ligands, imparting additional prevailing, valuable antimicrobial activities to reduce microbial growth. As a result, the inhibition zones in metal complexes were seen as superior to the free ligands. Data shown in table $2(a, b)$ correspond to fungal and bacterial screening, respectively, for both the synthesized compounds and ligands. The higher action of the synthesized complexes was possibly due to a better lipophilic environment for the complexes. The enhancement observed in the antimicrobial studies of the synthesized complexes over ligands may be due to chelation [21].

Overtone's perception of cell permeability says that a lipid membrane that surrounds the cell favors the access of only lipid-soluble materials, because this lipo-solubility is measured as a vital aspect of the antimicrobial study. Upon complexation, the polar nature of the metal ion corresponds to a larger size due to the ligand orbital's overlap and the unfinished distribution of 
the metal positive charge with groups of donor atoms [22]. In addition, the delocalization of $p$ electrons increased to complete chelation in metal complexes, along with its lipophilicity. Due to increased lipophilicity, the saturation also increases, resulting in blockage of the metalbonded areas of the microbial enzymes [23]. Furthermore, the solubility action and conductivity increase with ligand metal distance [24]. MIC data for the new complexes and the ligand are shown in table 3 (a) and (b).

A UV-vis spectrophotometer with an established DPPH method was used for viewing a free radical scavenging/hydrogen donating study for new mixed metal complexes [25]. Broad spectrum results were observed for the metal complexes; the $\mathrm{Ni}(\mathrm{II})$ complex showed good scavenging activity compared to $\mathrm{Co}(\mathrm{II})$. This activity increases with increasing compound concentration, as shown in table 4. Ligand/complexes proceed as hydrogen donors in the conversion of a radical in DPPH to its compressed form, DPPH-H. As DPPH receives electrons from the compound (antioxidant), the color changed, with a subsequent calculated absorbance change. Lower absorbance indicates higher free-radical scavenging. This activity depends on structural factors of compounds such as carboxylic groups and phenolic hydroxyl groups. Based on the above results for microbial studies and antioxidant activities, the metal complexes have higher antimicrobial activity than the ligand.

\section{CONCLUSION}

Newly synthesized compounds have been successfully characterized using various molecular techniques. Metal incorporated into ligand can have significant impact, serve multiple purposes and produce a high antimicrobial activity and possibly act as a powerful microbial agent.

\section{DECLARATIONS}

\section{Acknowledgement}

This project was funded by the Deanship of Scientific Research (DSR), Taibah University, AlMadinah Al-Munawarrah, Kingdom of Saudi Arabia (grant no. 6915). The authors appreciate DSR for this technical and financial support.

\section{Conflict of interest}

The authors declare that there is no conflict of interest associated with this work.

\section{Contribution of authors}

The authors declare that this work was performed by the authors named in this article and that all liabilities pertaining to claims relating to the content of this article will be borne by them.

For supplementary files, interested readers may contact the corresponding author via email.

\section{REFERENCES}

1. Cini R, Tamasi G, Defazio S, Hursthouse MB. Unusual coordinating behavior by three non-steroidal antiinflammatory drugs from the oxicam family towards copper(II). Synthesis, X-ray structure for copper(II)isoxicam, -meloxicam and-cinnoxicam-derivative complexes, and cytotoxic activity for a copper(II)piroxicam complex. J Inorg Biochem 2007; 101: 11401152.

2. Sonmez $M$, Levent, A, Sekerci M. Synthesis, Characterization, and Thermal Investigation of Some Metal Complexes Containing Polydentate Ono-Donor Heterocyclic Schiff Base Ligand. Russ. J Coord Chem 2004; 30: 655-659.

3. Sertçelik $M$, Delibaş NÇ, Necefoğlu $H$, Hökelek $T$. Diaquabis(4-formylbenzoato-kO 1) bis(nicotinamide-kN 1)nickel(II) Acta Crystallographica Section E 2012; 68: 946-947.

4. Sexton WA. Chemical Constitution and Biological Activity, 2nd ed., Spon, London, 1953.

5. Marek N, Carol L, Shunji S, Gunther D. Nicotinamide and 3-aminobenzamide interfere with receptor-mediated transmembrane signaling in murine cytotoxic $T$ cells: Independence of Golgi reorientation from calcium mobilization and inositol phosphate generation. Cell Immunol 1991; 132: 115-126.

6. I'de S, Atac A, Yurdakul S. Spectroscopic and structural studies on dichlorobis(nicotinamide)zinc(II). J Mol Struct 2002; 605: 103-107.

7. Kose DA, Ozturk B, Sahin O, Buyukgungor O. Mixed ligand complexes of coumarilic acid/nicotinamide with transition metal complexes. Synthesis and structural investigation. J Therm Anal Calorim 2014; 115: 15151524.

8. Jovanovic SV, Steenken S, Tosic M, Marjanovic B, Simic MG. Flavonoids as Antioxidants. J Am Chem Soc 1994; 116: 4846-4851.

9. Nakamoto K.Infrared and Raman Spectra of Inorganic and Coordination Compounds, Wiley Interscience, New York, USA, 1978.

10. Shiekh RA, Mohmmad YW, Sheikh S, Athar AH. Synthesis, characterization and biological screening of some Schiff base macrocyclic ligand based transition metal complexes as antifungal agents. Arab $\mathrm{J}$ Chem 2016; 9: S743-S751 
11. Kalsi PS. Spectroscopy of organic compounds, fourth ed., New Age International (P) Ltd., New Delhi, 1999.

12. Silverstein RM, Webster FX. Spectroscopic Identification of organic Compounds, 6th Edn, John Wiley and Sons. Inc. New York 1998; 482.

13. Sheikh RA, Shreaz S, Malik MA, Khan LA, Hashmi AA. Spectroscopic elucidation of new metal hetroscorpionates: A novel class of antifungal and antibacterial agents, J Chem Pharm Res 2010; 2: 133146.

14. Mann M. Electrospray: Its potential and limitations as an ionization method for biomolecules. Organic Mass spectrometry 1990; 25: 575-587.

15. Chaudhary A, Singh RV. Indian J Chem 2004; 43: 25292532.

16. Silverstein RM, Webster FX. Spectroscopic Identification of organic Compounds, 6th Edn, John Wiley and Sons. Inc. New York 1998.

17. Siddiqi ZA, Shadab SM. Indian J Chem 2004; 43: 22742279.

18. Kemp W. Organic Spectroscopy, Macmillan Press Ltd. 1975.

19. Sheikh RA, Shreaz S, Khan LA, Hashmi $A A$. Development and characterization of bioactive macrocyclic metal complexes, use as a potential drug. $J$ Chem Pharm Res 2010; 2(2): 172-185
20. Maurya RC, Rajput S. Oxovanadium (IV) complexes of bioinorganic and medicinal relevance: synthesis, characterization, and $3 D$ molecular modeling and analysis of some oxovanadium(IV) complexes involving O,O-donor environment. J Mol Struct 2004; 687: 35-44.

21. Sheikh S, Sheikh RA, Khan LA, Hashmi AA. Antifungal activity of $\alpha$-methyl trans cinnamaldehyde, its ligand and metal complexes: Promising growth and ergosterol inhibitors. Biometals 2011; 24: 923-933

22. Kralova K, Kwassova K, Svajlenova O, Vanco J. Biological Activity of Copper(II) -Salicylidene amino acidato Complexes. Reduction of Chlorophyll Content in Freshwater Alga Chlorella vulgaris and Inhibition of Photosynthetic Electron Transport in Spinach Chloroplasts. Chem Pap 2000; 58: 357-361.

23. Vaghasia $Y$, Nair $R$, Soni $M$, Baluja $S$, Chand $S$. Synthesis, structural determination and antibacterial activity of compounds derived from vanillin and 4aminoantipyrine. J Serb Chem Soc 2004; 69; 991-998.

24. Chohan $Z H$, Pervez $H$, Rauf A, Khan KM, Supuran CT. Isatin-derived Antibacterial and Antifungal Compounds and their Transition Metal Complexes, J Enzym Inhib Med Chem 2004; 39: 417-423.

25. Singh RP, Murthy KNC, Jayaprakasha GK. Studies on the antioxidant activity of pomegranate (Punica granatum) peel and seed extracts using in vitro models. J Agr Food Chem 2002; 50: 81-86. 